\title{
The Rise and Fall of Hypertension: Lessons Learned from Eastern Europe
}

\author{
Agata Bielecka-Dabrowa • Wilbert S. Aronow • \\ Jacek Rysz $\cdot$ Maciej Banach
}

Published online: 6 January 2011

(C) The Author(s) 2011. This article is published with open access at Springerlink.com

\begin{abstract}
Hypertension is a progressive cardiovascular syndrome that arises from many differing, but interrelated, etiologies. Hypertension is the most prevalent cardiovascular disorder, affecting $20 \%$ to $50 \%$ of the adult population in developed countries. Arterial hypertension is a major risk factor for cardiovascular diseases and death. Epidemiologic data have shown that control of hypertension is achieved in only a small percentage of hypertensive patients. Findings from the World Health Organization project Monitoring Trends and Determinants in Cardiovascular Diseases (MONICA) showed a remarkably high prevalence (about $65 \%$ ) of hypertension in Eastern Europeans. There is virtually no difference however, between the success rate in controlling hypertension when comparing Eastern and Western European populations. Diagnosing hypertension depends on both population awareness of the dangers of hypertension and medical interventions aimed at the detecting elevated blood pressure, even in asymptomatic patients. Medical compliance with guidelines for the treatment of hypertension is variable throughout Eastern
\end{abstract}

\footnotetext{
A. Bielecka-Dabrowa $\cdot$ M. Banach $(\bowtie)$

Department of Hypertension, WAM University Hospital in Lodz, Medical University of Lodz,

Zeromskiego 113,

90-549 Lodz, Poland

e-mail: maciejbanach@aol.co.uk

W. S. Aronow

Department of Medicine, New York Medical College,

Valhalla, NY, USA

J. Rysz

Department of Nephrology, Hypertension and Family Medicine,

Chair of Nephrology and Hypertension,

Medical University of Lodz,

Lodz, Poland

Europe. Prevalence of hypertension increases with age, and the management of hypertension in elderly is a significant problem. The treatment of hypertension demands a comprehensive approach to the patient with regard to cardiovascular risk and individualization of hypertensive therapy.

Keywords Eastern Europe $\cdot$ Epidemiology $\cdot$ Hypertension

\section{Introduction}

Hypertension is a progressive cardiovascular disease that arises from many differing but inter-related etiologies [1]. Early markers of the syndrome are often present before there is a sustained rise in blood pressure (BP) elevation. Hypertension therefore, cannot be classified solely using discrete BP parameters $[1,2]$. Progression of the syndrome is strongly associated with functional and structural cardiac and vascular abnormalities that damage the heart, kidneys, brain, vasculature, and other organs, which in turn leads to premature morbidity and death [1]. Hypertension is the most prevalent cardiovascular $(\mathrm{CV})$ disorder in developed countries and affects $20 \%$ to $50 \%$ of the adult population [2].

The European Society of Hypertension/European Society of Cardiology (ESH/ESC) guidelines [3] and the World Health Organization-International Society of Hypertension (WHO/ISH) guidelines [4] suggested that BP control can be described as adequate when systolic and diastolic BPs of $<140 \mathrm{~mm} \mathrm{Hg}$ and $<90 \mathrm{~mm} \mathrm{Hg}$, respectively, are achieved.

Furthermore the Joint National Committee (JNC) 7 and European Society of Hypertension/European Society of Cardiology (ESH/ESC) guidelines [3, 5] have suggested that systolic and diastolic BP values of $<130 \mathrm{~mm} \mathrm{Hg}$ and $<80$ 
$\mathrm{mm} \mathrm{Hg}$, respectively, should be the target range for special populations such as those affected by diabetes or renal disease. However, the current recommendations of the ESH (2009) indicate that we do not have enough data to demonstrate that a decreased in BP below 130/80 $\mathrm{mm} \mathrm{Hg}$ is connected with the reduction of cardiovascular events. Moreover, intensive BP lowering might increase CV events (the J-curve phenomenon) [6•].

Epidemiologic data have revealed that the BP control is achieved in only a small percentage of hypertensive patients $[6 \cdot, 7,8]$. In central European countries, BP control is only $20 \%$ to $25 \%$.

Many studies have demonstrated that elevated BP is a risk factor for coronary heart disease, heart failure, stroke, peripheral arterial disease, and renal failure in both men and women (Fig. 1) [9-13].

There is evidence that raised BP inversely correlates with cognitive function and that hypertension is associated with an increased incidence of dementia [14]. Data from studies involving 1 million patients have indicated that death from both CHD and stroke increases progressively and linearly from BP levels as low as $115 \mathrm{~mm} \mathrm{Hg}$ systolic and $75 \mathrm{~mm} \mathrm{Hg}$ diastolic [15]. Increased risks are present in all age groups, ranging from 40 to 89 years old. For every $20-\mathrm{mm} \mathrm{Hg}$ systolic or $10-\mathrm{mm} \mathrm{Hg}$ diastolic increase in BP, there is a doubling of mortality from both $\mathrm{CHD}$ and stroke. In addition, longitudinal data obtained from the Framingham Heart Study have indicated that BP values in the 130-139/ $85-89 \mathrm{~mm} \mathrm{Hg}$ range are associated with a more than twofold increase in relative risk from cardiovascular disease compared with those with BP levels below 120/80 $\mathrm{mm} \mathrm{Hg} \mathrm{[16].}$

A large number of randomized trials have confirmed that the main benefits of antihypertensive therapy are the result of BP lowering per se, independent of the class of drug used to lower blood pressure [17].

The odds ratio or the relative risk of CVD to the individual increases with the severity of hypertension, although the

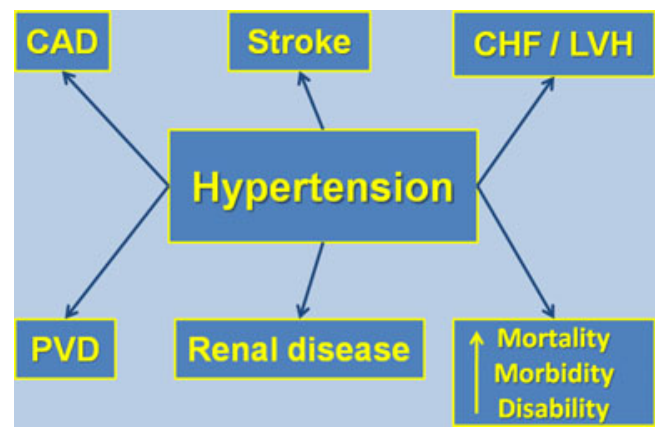

Fig. 1 Elevated blood pressure is a risk factor for many cardiovascular diseases. $C A D$ coronary artery disease, $C H F$ congestive heart failure, $L V H$ left ventricular hypertrophy, $P V D$ peripheral vascular disease attributable risk is greatest for mild hypertension due to its greater prevalence in the general population. Therefore, the burden of CVD arising from hypertension in the general population comes from those with relatively mild BP elevation [18].

Compared to normotensive individuals, those with an elevated BP have an increased tendency to have other risk factors for CVD (ie, diabetes, insulin resistance, dyslipidemia) $[19,20]$, together with various types and degrees of target organ damage. Because risk factors may interact positively with each other, the total $\mathrm{CV}$ risk of hypertensive patients is frequently high when BP elevation is only mild or moderate [21].

\section{The Prevalence and Awareness of Hypertension}

When comparing the prevalence of hypertension, one should be aware that this is heavily dependent on the definition of hypertension, the nature of the population being studied, the number of BP readings taken on each occasion and, finally, on the number of visits to the doctor [22•]. The prevalence of hypertension reported by Kearney et al. [23] varies widely, with rates as low as $3.4 \%$ in rural Indian men and as high as $72.5 \%$ in Polish women. Subregions with populations where consistently high mean systolic BP levels have been detected include parts of Eastern Europe and Africa. A comparative analysis of hypertension in North Americans aged 35 to 64 years showed a $60 \%$ lower prevalence of hypertension compared to similar subjects in European countries [23]. The difference in prevalence could not be explained by differences in body mass index (North America $27.1 \mathrm{~kg} / \mathrm{m}^{2}$, Europe $26.9 \mathrm{~kg} / \mathrm{m}^{2}$ ). Findings from the WHO project Monitoring Trends and Determinants in Cardiovascular Diseases (MONICA) Project showed a remarkably higher prevalence of hypertension in Eastern Europe (about 65\%), but virtually no difference in the rates of controlled hypertension among Eastern and Western populations [24, 25]. Epidemiologic studies (NATPOL III Plus) indicate that the prevalence of hypertension in Polish population is $67 \%$. Of all patients with hypertension in Poland, only $12 \%$ are successfully treated (Table 1) [26].

The data from the Polish multicenter, nationwide project WOBASZ assessed 13,545 subjects (6392 men and 7153 women) in the years 2003 to 2005 and showed that the average incidence of hypertension in Poland was about $36 \%$ [27]. Hypertension was more commonly detected in men $(42.1 \%)$ compared to women $(32.9 \%)$. This sex difference did depend, however, on the age at which the hypertension was detected [27]. The percentage of patients with controlled BP was low $(10 \%$ in men and $16 \%$ in women). This confirms the observations from the NATPOL 
Table 1 The effectiveness of diagnosis and treatment among adults Poles with hypertension in NATPOL III PLUS

\begin{tabular}{llll}
\hline Hypertension & Women & Men & Generally \\
\hline Not detected & $27 \%$ & $40 \%$ & $33 \%$ \\
Detected, not treated & $8 \%$ & $13 \%$ & $10 \%$ \\
Treated unsuccessfully & $51 \%$ & $37 \%$ & $45 \%$ \\
Treated successfully & $14 \%$ & $10 \%$ & $12 \%$ \\
\hline
\end{tabular}

(Adapted from Zdrojewski et al. [26])

III study, where BP control in the overall population of treated hypertensive patients was only $12 \%$ [26].

In Russia, $97.1 \%$ of the hypertensive population was above the recommended target level $(<140 / 90 \mathrm{~mm} \mathrm{Hg})$ at their first visit to an outpatient department. BP control was poorer in patients with a BP target of $<130 / 80 \mathrm{~mm} \mathrm{Hg}$ (20.1\%) than in those with a higher target BP (25.9\%) [28].

Detecting hypertension depends on both the awareness of population and the intervention of medical staff and should be aimed at the recording of elevated BP, even in symptomless patients. In the Czech Republic, there was an increase in the awareness of the dangers of hypertension (from $49.5 \%$ to $67.2 \%$ ) and the treatment of hypertension (from $29.3 \%$ to $49.3 \%$ ) from 1985 to 2001 [29]. Regional differences in BP levels have been observed in a number of developed countries. Differences were reported between urban and rural populations, with a tendency toward higher BP levels in urban areas.

\section{What Influences Compliance with Antihypertensive Therapy in Eastern Europe?}

The compliance of medical staff in following antihypertension treatment guidelines is variable. A study conducted on a random sample of Polish primary care doctors working in clinics contracted by the National Health Insurance Funds aimed to assess whether the doctors were following particular drug regimen guidelines. Doctors completed a questionnaire consisting of eight case vignettes describing patients with elevated BP [30॰]. The cases differed on three variables related to the level of blood pressure, the presence or absence of diabetes mellitus, and the presence or absence of other risk factors. Doctors were asked to give their treatment decision in each case. One hundred twenty-five doctors $(65 \%$ response rate) completed the questionnaire. Compliance with treatment guidelines was judged to be $51 \%$. Poor compliance with guidelines was noted for patients with diabetes mellitus. The level of blood pressure was the strongest predictor of drug treatment. Angiotensin-converting enzyme (ACE) inhibitors were the most frequently prescribed medications. Appropriate decisions were more commonly associated with medical practices in large cities [30॰].

Insufficient use of diuretics in combination antihypertensive therapy is a main cause of poor BP control in Russia. The objective of the Russian ARGUS-2 [31•] study was to demonstrate that a rational use of a thiazide-like diuretic, indapamide sustained release (SR), alone or in combination, improved BP control in patients with difficult-to-control hypertension. The open-label, non-comparative 3-month study without preliminary washout included 1438 hypertensive patients (mean age $57.3 \pm 10.7$ years, mean BP $158.8 \pm 14.2 / 93.4 \pm 10.0 \mathrm{~mm} \mathrm{Hg}$ ), with difficult-to-control arterial hypertension who had never been treated with diuretics. Throughout the study, patients received indapamide SR $1.5 \mathrm{mg}$ daily. BP control was defined as $<140 / 90 \mathrm{~mm} \mathrm{Hg}$ for all patients and $<130 / 80 \mathrm{~mm} \mathrm{Hg}$ for those with diabetes mellitus or chronic nephropathy [31•]. Approximately $75.7 \%$ of patients also were prescribed an ACE inhibitor or an angiotensin II receptors blocker, $43.9 \%$ a calcium channel blocker, and $32.8 \%$ a $\beta$-blocker. The study demonstrated the value of including the thiazide-like diuretic indapamide SR in a combined antihypertensive regimen to control BP in hypertensive patients with added cardiovascular risk factors whose hypertension is difficult to treat. In 3 months after indapamide SR administration, average BP level decreased to $131.8 \pm 9.7 / 80.5 \pm 6.9 \mathrm{mmHg}$, and $84.5 \%$ of the study population achieved BP control. BP was controlled in $91.9 \%$ of patients with isolated systolic hypertension $(n=477), 74.8 \%$ of those with diabetes ( $n=214$ ), $75.6 \%$ of those with chronic nephropathy $(n=82)$, and $85.1 \%$ of patients with metabolic syndrome $(n=745)$ [31•].

In Russia, achieving a BP target was associated with combination therapy, a higher rate of diuretic administration, and more frequent visits to the physician [28]. During hospitalization, a target BP of $<140 /<90 \mathrm{~mm} \mathrm{Hg}$ was achieved in $87.1 \%$ of patients, and $<130 /<80 \mathrm{~mm} \mathrm{Hg}$ in $76.2 \%$ of patients. Low adherence to antihypertensive treatment, lack of patient knowledge about the risks related to hypertension, and financial problems were identified as the main barriers to improve control of BP. Patients considered financial issues related to antihypertensive treatment as being much less important compared to their physicians [28].

Bajraktari et al. [32] assessed the quality of the management of hypertension in patients hospitalized in the cardiology service in Kosovo. They studied patients who were mainly referred from general practitioners, internists, and cardiologists for a better treatment of hypertension or because hypertension was associated with other comorbidities needing hospitalization. This retrospective study included 938 consecutive hypertensive patients $(63.1 \pm 11.3$ years, 55.1\% women). Angiotensin-converting enzyme inhibitors (ACEI) and/or angiotensin II receptor blockers 
were the drugs most commonly prescribed in their study group $(83 \%)$. $\beta$-blockers (BB) were the second group of the drugs that were prescribed $(71 \%)$, followed by diuretics $(60 \%)$, and calcium channel blockers $(26 \%)$. The most frequent drug combination used was ACEI, BB, and diuretic $(30.5 \%)$. Adequate systolic and diastolic blood pressures were achieved in $50 \%$ of patients. Multivariate analysis identified diabetes, (odds ratio $[\mathrm{OR}]=0.479 ; 95 \% \mathrm{CI}, 0.339-0.677$; $P<0.001)$, creatinine level $(\mathrm{OR}=0.997 ; 95 \% \mathrm{CI}, 0.996$ $0.999 ; P=0.001)$, and combination therapy $(\mathrm{OR}=0.445 ; 95 \%$ CI, $0.253-0.774 ; P=0.046)$ as independent correlates of in-hospital poor BP control [32].

It has been demonstrated that the optimal BP control was far better during in-hospital treatment of hypertensive patients than in those treated in primary health care units [32-35]. Moreover, the behavior of physicians attending hypertensive patients (including careful examination and detailed information given on the rules of hypertension therapy and hypertension complications) was shown to be a factor that may influence better BP control in in-hospital hypertension units [36, 37].

\section{Hypertension in the Elderly}

The management of hypertension in the elderly is a significant problem in the countries of Eastern Europe. Prevalence of hypertension increases with age, rising steeply after the age of 50 years, and affects more than $50 \%$ of this population. In adulthood, systolic and diastolic BP tends to rise with age. The increase is somewhat greater in systolic BP, whereas diastolic BP remains almost unaltered from age 50 years and upward. Aging results in a progressive increase in pulse pressure, which is the difference between systolic and diastolic pressure [24, 38].

Guidelines for the management of hypertension include areas where the evidence for or against treatment in certain types patient groups is inconclusive. This is especially the case of older patients with hypertension [3, 4].

Although a large number of randomized trials that have included hypertensive patients aged $\geq 60$ years have shown that antihypertensive drugs reduce cardiovascular morbidity and mortality, health care professionals are often reluctant to prescribe adequate antihypertensive therapy [39].

In a meta-analysis by the Blood Pressure Lowering Treatment Trialists' Collaboration (BPLTTC) [40], the effects of different drugs in reducing BP in older and younger adults were analyzed. The reduction in BP and the relative risk reduction of a cardiovascular event with various antihypertensive drugs occurred independently of patient age. The benefits of the antihypertensive regimens were widely comparable across age groups independent of the drug class [40]. The BPLTTC analysis strongly suggested that there should be early and aggressive management of hypertension irrespective of age [40].

The Hypertension in the Very Elderly Trial (HYVET) [41] was a double-blind, placebo-controlled trial that included 3845 patients aged $>80$ years who had sustained systolic BP $\geq 160 \mathrm{~mm} \mathrm{Hg}$ or diastolic hypertension (90-109 $\mathrm{mmHg}$ ). Patients were randomized to either SR indapamide $1.5 \mathrm{mg}$ or placebo. In the first group, perindopril was added as needed. Results of the HYVET study proved that early and systematic therapy of hypertension with indapamide or indapamide and perindopril in this age group reduces the risk of all-cause mortality $(21 \%)$, fatal and non-fatal stroke $(30 \%)$, and mortality and heart failure (64\%) development. The treatment of hypertension demands comprehensive approach to the patient regarding global cardiovascular risk and individualization of hypertensive therapy [41]. These studies were very important as they confirmed that we should treat hypertension irrespective of age, but we still do not know what should be the target BP in elderly patients. However, it is worth noting that on the basis of data from HYVET, in which the systolic BP was actually lowered to $143 \mathrm{~mm} \mathrm{Hg}$, American recommendations suggest lowering the systolic BP in persons aged 80 years and older to 140 to $145 \mathrm{~mm} \mathrm{Hg}$ if tolerated. This is important data for Eastern Europeans countries, because there is no current standard for optimal therapy of elderly patients [41-44].

What is the best drug to treat hypertension in older and younger adults? There are a few pathophysiologic mechanisms that are specific in the elderly. This includes the agerelated increase in postsynaptic $\alpha$-adrenoceptor-mediated and calcium influx-dependent vasoconstriction, as well as a decrease in plasma renin activity. The recently revised British guidelines [42] suggested that patients younger than 55 years should be treated with ACE inhibitors and older patients with diuretics or calcium channel blockers. On the other hand, other European guidelines [3, 4] suggest that evidence for an age-dependent strategy in the choice of antihypertensive drugs is as yet insufficient. In fact, benefits have been demonstrated in older hypertensive patients for several drug classes such as diuretics, calcium channel blockers, ACE inhibitors, angiotensin receptor blockers (ARB), and BBs [43-46].

The first drug of choice in older patients often needs to be precisely tailored to individual characteristics, as older adults frequently have other risk factors, target organ damage, and other associated clinical conditions. Additionally, many patients will need two or more drugs to control BP, since in the very old it can be particularly difficult to obtain a systolic BP of lower than $140 \mathrm{mmHg}$ $[39,47,48]$. 


\section{Conclusions}

Despite continuously accumulating data, many decisions on hypertension management must still be taken without the support of evidence from available clinical trials. The problem with the optimal control and treatment of hypertension is especially important for Central and Eastern European countries, given the high prevalence of hypertension, but the reasons of the problems are the same as in Western European countries and the United States. These reasons, and obviously the problems of compliance and therapeutic inertia are the most important reasons that hypertension remains the most important risk factor for cardiovascular disease and the greatest contributor to mortality worldwide [49•, 50•, 51-55].

Disclosure Agata Bielecka-Dabrowa reports no potential conflict of interest relevant to this article. Wilbert S. Aronow reports no potential conflict of interest relevant to this article. Jacek Rysz reports no potential conflict of interest relevant to this article. Maciej Banach reports no potential conflict of interest relevant to this article.

Open Access This article is distributed under the terms of the Creative Commons Attribution Noncommercial License which permits any noncommercial use, distribution, and reproduction in any medium, provided the original author(s) and source are credited.

\section{References}

Papers of particular interest, published recently, have been highlighted as:

- Of importance

1. Bruce Goldfarb. ASH Panel Proposes New Hypertension Definition. 2005; 2: 1-7.

2. From the Centers for Disease Control and Prevention. Decline in deaths from heart disease and stroke-United States, 1990-1999. JAMA 1999; 282: 724-6.

3. Mancia G, Grassi G. The new European Society of Hypertension/ European Society of Cardiology (ESH/ESC) Guidelines. Ther Adv Cardiovasc Dis. 2008;2(1):5-12.

4. Guidelines Subcommittee, World Health OrganizationInternational Society of Hypertension Guidelines for the management of hypertension. J Hypertens 1999; 17: 151-83.

5. Chobanian AV, Bakris GL, Black HR, et al.: Seventh report of the Joint National Committee on Prevention, Evaluation, and Treatment of High Blood Pressure. Hypertension 2003; 42:1206-1252.

6. Mancia G, Laurent S, Agabiti-Rosei E, et al. Reappraisal of European guidelines on hypertension management: a European Society of Hypertension Task Force document. J Hypertens 2009; 27: 2121-58. These are the current guidelines of European Society of Hypertension, and they recommend new borderline issues on hypertension diagnosis and management.

7. Marques-Vidal P, Tuomilehto J. Hypertens awareness, treatment and control in the community: is the "rule of halves" still valid? J Hum Hypertens 1997; 11: 213-20.
8. Mancia G, Sega R, Milesi C, Cesana S, Zanchetti A. Blood pressure control in the hypertensive population. Lancet 1997; 349: 454-7.

9. MacMahon S, Peto R, Cutler J, et al. Blood pressure, stroke, and coronary heart disease. Part 1 . Prolonged differences in blood pressure: prospective observational studies corrected for the regression dilution bias. Lancet 1990; 335: 765-74.

10. Kannel WB. Blood pressure as a cardiovascular risk factor: prevention and treatment. JAMA 1996; 275: 1571-6.

11. Assmann G, Schulte H. The Prospective Cardiovascular Münster (PROCAM) study: prevalence of hyperlipidemia in persons with hypertension and/or diabetes mellitus and the relationship to coronary heart disease. Am Heart J 1988; 116: 1713-24.

12. Walker WG, Neaton JD, Cutler JA, Neuwirth R, Cohen JD. Renal function change in hypertensive members of the Multiple Risk Factor Intervention Trial. Racial and treatment effects. The MRFIT Research Group. JAMA 1992; 268: 3085-91.

13. National High Blood Pressure Education Program Working Group. Arch Intern Med. 1993;153:186-208.

14. Skoog I, Lernfelt B, Landahl S, et al. 15-year longitudinal study of blood pressure and dementia. Lancet 1996; 347: 1141-5.

15. Lewington S, Clarke R, Qizilbash N, Peto R, Collins R.; Prospective Studies Collaboration. Age-specific relevance of usual blood pressure to vascular mortality: A meta-analysis of individual data for one million adults in 61 prospective studies. Lancet 2002; 360: 1903-13.

16. Vasan RS, Larson MG, Leip EP, et al. Impact of high-normal blood pressure on the risk of cardiovascular disease. N Engl J Med 2001; 345: 1291-7.

17. Kjeldsen SE, Reims HM, Fagard R and Mancia G. Hypertension. In: Camm AJ, Luscher TF, Serruys PW. The ESC textbook of cardiovascular medicine. P 271-300.

18. Kannel WB. Update on hypertension as a cardiovascular risk factor. In: Manual of Hypertension. Mancia G (ed.). Churchill Livingstone: London 2002; 4-19.

19. Isomaa B, Almgren P, Tuomi T, et al. Cardiovascular morbidity and mortality associated with the metabolic syndrome. Diabetes Care 2001; 24: 683-9.

20. Cuspidi C, Ambrosioni E, Mancia G, Pessina AC, Trimarco B, Zanchetti A; APROS Investigators. Role of echocardiography and carotid ultrasonography in stratifying risk in patients with essential hypertension: the Assessment of Prognostic Risk Observational Survey. J Hypertens 2002; 20: 1307-14.

21. Anderson KM, Wilson PW, Odell PM, Kannel WB. An updated coronary risk profile. A statement for health professionals. Circulation 1991; 83: 356-62.

22. - Cífková R. Epidemiology and risk of hypertension. Arch Med Sci 2009; 5, 2A: S 199-S 211. This article presents the current data on epidemiology and risk of hypertension, including data from Eastern European countries.

23. Kearney PM, Whelton M, Reynolds K, Whelton PK, He J. Worldwide prevalence of hypertension: a systematic review. J Hypertens 2004; 22: 11-9.

24. Wolf-Maier K, Cooper RS, Banegas JR, et al. Hypertension prevalence and blood pressure levels in 6 European countries, Canada and the United States. JAMA 2003; 289: 2363-9.

25. Strasser T. Hypertension: the East European experience. Am J Hypertens 1998; 11: 756-8.

26. Zdrojewski T, Bandosz P, Szpakowski Pet al. The prevalence of major risk factors for diseases of the cardiovascular system in Poland. Test results NATPOL PLUS. Kardiol. Pol. 2004; 61(supl. IV): $15-17$

27. Tykarski A, Posadzy-Małaczyńska A, Wyrzykowski B et al. Prevalence of hypertension and the effectiveness of its treatment in adults in our country. Results of WOBASZ study. Kardiol. Pol. 2005; 63: S614-S619. 
28. Kobalava ZhD, Kotovskaia IuV, Starostina EG et al. Problems of a physician-patient interaction and control of arterial hypertension in Russia. Main results of scientific-practical program ARGUS-2. Kardiologiia. 2007;47(3):38-47.

29. Cífková R, Skodová Z, Lánská V, et al. Trends in blood pressure levels, prevalence, awareness, treatment and control of hypertension in the Czech population from 1985 to 2000/01. J Hypertens 2004; 22: 1479-85.

30. - Windak A, Gryglewska B, Tomasik T, Narkiewicz K, Yaphe J, Grodzicki T. Competence of Polish primary-care doctors in the pharmacological treatment of hypertension. J Eval Clin Pract. 2010;16:25-30. The authors present the problem with compliance and therapeutic inertia in Poland.

31. - Kobalava ZD, Kotovskaya YV, Villevalde SV, Moiseev VS; ARGUS-2 Study. Treating hypertension by rational use of diuretics: results of the Russian ARGUS-2 Study. Curr Med Res Opin. 2009;25:2229-37. The authors present the data on management of hypertension in Russia.

32. Bajraktari G, Sylejmani X, Thaçi K, Elezi S, Ndrepepa G. The quality of arterial hypertension treatment in cardiology service in Kosovo - a single center study - Original Investigation. Anadolu Kardiyol Derg 2009; 9: 96-101

33. Kumpusalo E, Parnanen H, Takala J. Treatment situation of hypertensive patients in Finnish primary health care. Blood Press 1997; 1 (Suppl): 35-9.

34. Cuspidi C, Lonati L, Sampieri L, Macca G, Valagussa L, Zaro T, et al. Blood pressure control in a hypertension hospital clinic. J Hypertens 1999; 17: 835-41.

35. Singer GM, Izhar M, Black HR. Goal-oriented hypertension management. Translating clinical trials to practice. Hypertension 2002; 40: 464-9.

36. Berlowitz DR, Ash AS, Hickey EC, Friedman RH, Glickman M, Kader B, et al. Inadequate management of blood pressure in a hypertensive population. N Engl J Med 1998; 339: 1957-63.

37. Coca A. Actual blood pressure control: are we doing things right? J Hypertens 1998; 16 (Supp11): S45-S51.

38. Bulpitt CJ, Fletcher AE. Prognostic significance of blood pressure in the very old. Implications for the treatment decision. Drugs Aging. 1994;5: 184-191.

39. Verdecchia P, Gentile G, Angeli F, Reboldi G. Should we prefer different drugs to treat hypertension in older and younger adults? Practical implications of clinical trials: European perspective. Pol Arch Med Wewn, 2008; 118: 513-516

40. Blood Pressure Lowering Treatment Trialists' Collaboration. Effects of different regimens to lower blood pressure on major cardiovascular events in older and younger adults: meta-analysis of randomised trials. BMJ. 2008; 336: 1121-1123.

41. Beckett N, Peters R, Fletcher AE et al. for the HYVET Study Group. Treatment of Hypertension in Patients 80 Years of Age or Older. N Engl J Med 2008; 358:1887-1898
42. JBS 2: Joint British Societies' guidelines on prevention of cardiovascular disease in clinical practice. Heart. 2005; 91 (Suppl 5): v1-v52.

43. Hansson L, Lindholm LH, Ekbom T, et al. Randomised trial of old and new antihypertensive drugs in elderly patients: cardiovascular mortality and morbidity the Swedish Trial in Old Patients with Hypertension-2 study. Lancet. 1999; 354: 1751-1756.

44. Major outcomes in high-risk hypertensive patients randomized to angiotensin-converting enzyme inhibitor or calcium channel blocker vs. diuretic: The Antihypertensive and Lipid-Lowering Treatment to Prevent Heart Attack Trial (ALLHAT). JAMA. 2002; 288: 2981-2997.

45. Lithell H, Hansson L, Skoog I, et al. The Study on Cognition and Prognosis in the Elderly (SCOPE): principal results of a randomized double-blind intervention trial. J Hypertens. 2003; 21: $875-886$

46. Papademetriou V, Farsang C, Elmfeldt D, et al. Stroke prevention with the angiotensin II type 1-receptor blocker candesartan in elderly patients with isolated systolic hypertension: the Study on Cognition and Prognosis in the Elderly (SCOPE). J Am Coll Cardiol. 2004; 44: 1175-1180

47. Fagard RH, Van Den Enden M, Leeman M, Warling X. Survey on treatment of hypertension and implementation of World Health Organization/International Society of Hypertension risk stratification in primary care in Belgium. J Hypertens. 2002; 20: 1297-1302.

48. Mancia G, Grassi G. Systolic and diastolic blood pressure control in antihypertensive drug trials. J Hypertens. 2002; 20: 1461-1464.

49. - Banach M, Kjeldsen SE, Narkiewicz K. Controversies in Hypertension Treatment. Curr Vasc Pharmacol 2010; 8:731-2. The authors present the current problems in the diagnosis, control, management, treatment, and prevention of hypertension complications in hypertensive patients.

50. • Gaciong Z, Symonides B. Hypertension 2010: What was New for the Cardiologist? Expert Opin Pharmacother 2010; 11:2579 97. The authors present the current achievements in hypertension management in 2010, including the current guidelines of the European Society of Hypertension.

51. Desai RV, Banach M, Ahmed MI, et al. Impact of baseline systolic blood pressure on long-term outcomes in patients with advanced chronic systolic heart failure (insights from the BEST trial). Am J Cardiol 2010;106:221-7.

52. Bielecka-Dabrowa A, Aronow WS, Rysz J, Banach M. Current place of beta-blockers in the treatment of hypertension. Curr Vasc Pharmacol 2010; 8:733-41.

53. Stepien M, Banach M, Jankowski P, Rysz J. Clinical implications of non-invasive measurement of central aortic blood pressure. Curr Vasc Pharmacol 2010; 8:747-52.

54. Sethi A, Arora RR. Ambulatory blood pressure as a predictor of cardiovascular risk. Arch Med Sci 2009; 5: 3-9.

55. Banach M, Rysz J. Current Problems in Hypertension and Nephrology. Expert Opin Pharmacother 2010; 11:2575-8. 